\title{
Aproximación a la cultura del trabajo y los cambios productivos en Villa Chagüitillo. ${ }^{1}$
}

Joseph Orlando Torres Obando

\begin{abstract}
Resumen:
Villa Chagüitillo es una comunidad semi-rural. La cultura de trabajo que se ha desarrollado en esta localidad corresponde al rasgo productivo agropecuario, marcado a partir de una identidad campesino-indígena, sin dejar de lado aspectos urbanísticos que ha penetrado por medio del mercado. Para entender esta cultura de trabajo en esta localidad, es necesario ver de manera retrospectiva el proceso de transformación productiva, requiriendo para ello, de un manejo metodológico de etnografía con análisis sistémico y apoyo del método comparativo, que en conjunto con técnicas provenientes de la historiografia, develan las razones de los cambios de políticas públicas dirigidas a lo rural y el rumbo que apunta la dinámica rural actual de Chagüitillo.
\end{abstract}

Palabras claves: cultura del trabajo, dinámica rural, transformación productiva, políticas agrarias.

\section{Abstract:}

Villa Chagüitillo is a semi-rural community, work culture that has developed in this locality corresponds to agricultural production traits, which have been marked from a peasant-indigenous identity, without neglecting urban areas they have penetrated through the market. To understand this culture of work in Chagüitillo, you need to turn your gaze back over the process of productive transformation, and this, undoubtedly, it requires a methodological management of ethnography with systems analysis with support from the comparative method, and together with techniques of historiography; to uncover the reasons that surfaced the current panorama, as were the changes in public policies directed to rural, so that glimpse points where the current rural dynamics Chagüitillo.

Key words: work culture, rural dynamic, productive transformation, agrarian politics.

\section{Introducción}

El presente ensayo es fruto de la convocatoria que la Facultad de Humanidades y Ciencias Jurídicas, hiciera en junio pasado, a docentes para participar, en el XIX Congreso Científico de la Facultad de Humanidades y Ciencias Jurídicas. El texto fue leído en la mesa correspondiente a: "Investigación clásica tradicional vs. Investigación inter, trans y multidisciplinar: retos y desafíos en la reflexión estudiantil". Esta mesa corresponde al espacio designado por los organizadores del Congreso a los estudiantes.

El origen de este trabajo se encuentra en una investigación realizada, en el marco de la asignatura Prácticas de Especialización I. Se podría decir que es un "paper" para ser presentado en el salón de clase para

1 Dedicado a todos mis colaboradores de Villa Chagüitillo, y especial agradecimiento a mis padres, a mis mentores académicos. A mi novia Alejandra Pérez. Soy el producto de todos ellos. 
su evaluación, y dentro de ese proceso de organización y análisis de trabajo, el tema perfilado a la luz de la información recabada se titulaba: "Gestión de los elementos culturales en función del turismo comunitario en Chagüitillo, 2015".

Pese a que -como se señaló arriba-- se usa información recolectada para una investigación en particular, el material recabando y otro usado, permite abordar con suficiente autonomía y hacer los vínculos que sean pertinente con el trabajo original. El punto central de este trabajo es el mostrar la manera en que se modifican las políticas públicas, y dentro de ellas, las políticas agrarias, determinantes porque marcan la dinámica en los territorios rurales y semirurales, como es el caso de la comunidad de Villa Chagüitillo.

Entre los métodos en que se apoyó el estudio, están la etnografía con análisis sistémico, lo cual ayuda a explicar el proceso de transformación en un contexto específico. El método comparativo donde más que comparar espacialidad se compara temporalidad. Durante la etapa de campo, una de las técnicas utilizadas, además de las insustituibles entrevistas y observación directa, fue el grupo focal; en la que se les pidió a los participantes, construir una línea de tiempo (técnica de la historiografía) referente a los tipos de trabajo existente desde la década del 70 hasta la actualidad (segunda década del siglo XXI).

El proceso de redacción de este escrito sigue una estructura lineal de tiempo, completando los datos con las entrevistas en profundidad y las encuestas. Durante el análisis se comparan los tipos de trabajo prevalecientes en cada época, explicando las razones que dieron a luz a esas dinámicas laborales.

Aspectos conceptuales

Villa Chagüitillo es una comunidad semirural que está bajo la jurisdicción del municipio de Sébaco, Matagalpa. En esta localidad, los campesinos e indígenas, sujetos culturalmente diferenciados (dentro de la comunidad hay la aceptación de la identidad cultura indígena, representada en grupos que se auto reconocen como tal y piden ser reconocidos) comparten un mismo proceso de trasformación productiva. Este proceso se evidencia con mayor claridad en las últimas décadas del siglo XX.

Es importante iniciar el trabajo, definiendo a los sujetos involucrados en este estudio. El campesino como sujeto, ha sido definido innumerables veces por diferentes estudiosos de lo rural, pero para este ensayo, debemos entenderlo a partir de la definición dada por Erich Fromm y Michael Maccoby (1990) quienes señalan que campesinos [son ] aquellos vecinos de un pueblo cuya ocupación principal es la agricultura, aunque también pueden trabajar como alfareros o pescadores. ( pág. 16).

De lo anterior se desprende que al hacer referencia al sujeto campesino, creamos una imagen de él relacionado con las labores de la tierra y la pesca. Esta definición de Fromm y Michael Maccoby (1990) incorpora, además del pescador al alfarero, en contraposición a la creencia mayoritaria que el campesino era únicamente el que labraba la tierra.

En relación a la manera de cómo se entiende y/o modela para el presente estudio, al sujeto indígena, se hará uso de la definición dada por la OIT (1953):

Indígenas son los descendientes de la población aborigen que vivía en un país determinado en el momento de su colonización o conquista (o sucesivas conquistas) por algunos de los ancestros no-indígenas que en el presente detentan el poder político y económico. ( pág. 26)

De acuerdo al concepto sugerido por la OIT, el indígena es el descendiente del pueblo aborigen $\mathrm{u}$ originario, $\mathrm{y}$ que por su situación de marginación, carece de poder o influencia política. Su condición subalterna frente a los grupos hegemónicos 
herederos de los intereses y pensamiento de los conquistadores, está reflejada en la invisibilización histórica a que ha sido sometido.

Volviendo a Fromm y Maccoby, ellos señalan una diferencia bien marcada entre campesino e indígena:

...lo que distingue al campesino de la mayoría de indígenas es que depende económica, cultural y políticamente de la sociedad urbana. Debe vender lo que produce en los mercados urbanos, pero a cambio necesita dinero para comprar los productos de la ciudad. (Fromm \& Maccoby, 1990, pág. 16)

La verdadera diferencia entre ambos sujetos, indígenas y campesinos (al menos refiriéndonos a Chagüitillo) será una cuestión meramente cultural. La confluencia de su doble condición, no lo inhibe, ni le perjudica su inserción dentro de la estructura sociopolítica imperante. Se dan casos en que algunos no se autoafirmen como campesino, sino como indígena o a la inversa y aquí viene el tema de la frontera cultural y sus implicaciones políticas, acerca de estas categorías que están en juego en este trabajo Ahora bien, tanto el que se identifica como campesinos como el que se siente indígenas (incluso el que se vea en la doble condición) en la comunidad de Chagüitillo, han estado históricamente ha estado subordinados al poder central, sea estatal o de otra índole. Esta condición política o cultural, no ha favorecido a estos sujetos, sino que ha creado situaciones conflictivas o ambiguas en diferentes momentos de la historia de este pueblo.

En un contexto como el nicaragüense la anterior situación y condición, se expresa de la siguiente manera:

La mayoría de los nicaragüenses tienen necesidades inmediatas, las que deben "resolverse" inmediatamente. Esto se presta a que la política sea dominada por relaciones clientelares y de apegos personales: es decir, relaciones que caracterizan a las sociedades tradicionales. (Cruz-Sequeira, 2005, pág. 1)

Como bien señala Cruz-Sequeira, las prácticas políticas han tendido a favorecer a ciertos sectores interesados o privilegiados, dejando desprovistos a las mayorías que no tienen relación alguna con los poderes fácticos. Esta situación política, dentro del contexto de Villa Chagüitillo, objeto del estudio, refleja un proceso de transformación productiva generada por la puesta en marcha de políticas públicas destinada a favorecer principalmente a los sectores urbanos (sector principal del pueblo). Esto ha generado una nueva cultura de trabajo dentro de los sectores rurales y semi-rurales de Villa Chagüitillo.

De lo anterior, la cultura del trabajo, pudiera entenderse como: Modelos cognitivos, morales y motivacionales con los que los hombres definen, valoran y orientan el trabajo - el suyo y el de los demás - los resultados obtenidos y sus composiciones, su situación social y su contenido profesional. (Moreno, 1997, pág. 20)

\section{Proceso de transformación campesino- indígena: década del 70 hasta la actualidad}

Durante la década de los 70 en Nicaragua, ya en la etapa de crisis de la dictadura somocista, el gobierno mantuvo en interés de continuar la expansión de la siembra de algodón en diversas zonas del país, de manera particular el Pacífico. El latifundismo imperaba como uno de las formas más importante de concentración de la tierra y los dueños, ---terrateniente también---, realizaban prácticas de cultivo en el territorio de Chagüitillo.

Los campesinos, pequeños productores de Villa Chagüitillo, dueños de pequeñas parcelas o lotes, a diferencia de los 
terratenientes, basaban su producción en el cultivo de granos básicos para autoconsumo. Don Larry Monje de 30 años de edad (originario de la comunidad y de identidad indígena) menciona que en la época de los 70 lo que predominaba era el cultivo y corte de algodón (Monje, 2015).

Se ha señalado que el algodón era el rubro más importante, desde el punto de vista productivo y comercial desde la década del 50 hasta los 70. Vale recalcar que la actividad algodonera permanece vigente en el imaginario colectivo de quienes practicaban la agricultura a gran escala. En cambio, los pequeños productores como don Luis López Blandón de 80 años de edad (campesino originario de la comunidad), quien dedicó toda su vida a la actividad agrícola hasta jubilarse, señala: Los tipos de trabajo en Chagüitillo, históricamente, han sido la siembra de maíz, millón y hortalizas. En los años setenta se sembraba el arroz, maíz y frijoles. (Blandón, 2015).

Los obreros agrícolas que trabajaban en las fincas de los grandes productores de algodón, producían en pequeñas parcelas, granos básicos y en algunas ocasiones, cultivaban millón y ajonjolí para el autoconsumo.

Una aproximación a la situación productiva y de tenencia de la tierra existente durante la época de los 70 en Chaguitillo, pudiera ser la siguiente: a) una estructura social de tipo "señorial" por la figura del terratenientes, b) el monocultivo del algodón como rubro comercial principal, y c) la estrategia de agricultura de subsistencia (basada de maíz, arroz y frijoles) que marca la identidad campesino-indígena.

La agricultura de subsistencia del pequeño productor de granos básicos, le sirve únicamente para satisfacer necesidades de alimentación para él y su familia, durante cierto tiempo del año. Este tipo de producción a pequeña escala, no le permite genera excedentes para comercializar y suplir necesidad de otra índole cubriendo todo el año., razón por la cual debe de vender su fuerza de trabajo al terrateniente. Esta situación en la tenencia de la tierra cambiará con el triunfo de la Revolución Popular Sandinista en 1979, creando un nuevo escenario político y económico en la década del 80'.

La Revolución Popular Sandinistas implementó la reforma agraria, cambiando las políticas públicas dirigidas al campo, y modificando ciertas estructuras sociales, económicas, afectando la tenencia de la tierra. Las políticas del gobierno revolucionario, implicó una transformación histórica en la dinámica productiva. Para entender el significado de la reforma agraria, veamos lo dice García (1990):

La naturaleza de núcleo esencial de la reforma agraria, presupone el que hayan desaparecido las antiguas formas del monopolio señorial sobre la propiedad de la tierra, en el agua y los bosques, $\mathrm{y}$ el que funcionen, realmente, en un mercado de tierras como mecanismo redistribuidor de los recursos físicos y un mercado de trabajo rural como mecanismo redistribuidor de los ingresos agrícolas (pág. 231)

Efectivamente, la reforma agraria significó la expropiación de tierras en manos de terratenientes, muchas de estas tierras pasaron a manos de cooperativas conformadas por campesino-indígenas en Villa Chagüitillo. La tenencia de la tierra había cambiado, y pasaba a tener un carácter colectivo, cooperativo. El algodón, rubro de mayor peso económico en décadas anteriores, cuya columna vertebral eral los latifundios, da paso a las nuevas formas colectivas $y$ social de propiedad y de producción, la cual estaría centrada en la producción de granos básicos, el café entre otros. El informante Blandón (2015) señala: En los setenta las tierras eran de un turco de nombre Ajar Zamare... en los ochenta se distribuyeron tierras por cooperativa y hubo un desarrollo en el trabajo, la reforma 
agraria fue la que nos dio tierras para trabajar. (Blandón, 2015).

Además de los beneficios y acopiadoras de café, en la década de los ochenta, se crearon complejos agroindustriales estatales y se fomentó en mayor medida el cultivo de hortalizas, principalmente entre los pequeños productores. De igual manera empresas agroindustriales privadas tenían participación en la producción de hortalizas. Es importante destacar que la producción de hortaliza se generalizó en gran parte del valle de Sébaco, compitiendo en importancia con la producción arrocera, rubro importante para la zona.

Los campesinos cooperados que tenían derecho a posesión de la tierra, en sus diferentes formas de propiedad, permitido por el gobierno revolucionario, recibían financiamiento estatal, con el fin de producir para el autoconsumo, y generar un excedente para la comercialización. Esta nueva situación, hacía que no tuvieran necesidad de vender su fuerza de trabajo a los complejos agroindustriales, o empresas beneficiadoras de café.

Don Luis Blandón habla sobre una empresa exportadora de tomate situada en Granada, que tuvo gran influencia en la producción de este rubro. En su testimonio corrobora la presencia de las empresas agroindustriales en su participación en la producción y comercialización del producto: ... En nuestra cooperativa cosechábamos el tomate y se le llevaba a la fábrica de Granada, el maíz y frijol era para autoconsumo, y si se sacaba bastante se le vendía a los comerciantes de Sébaco... (Blandón, 2015) Dentro del mundo de los cooperados, los espacios de interacción se modificaban al ritmo en que las unidades domésticas distribuían sus roles, integrando a todos los miembros de la familia en la actividad productiva. Cada cooperativa tenía su siembra destinada al mercado, siembra para el autoconsumo y sus compradores fijos, fuesen empresas mayoristas reconocidas o comerciantes minoristas del mercado de Sébaco. En estas actividades productivas, los cooperados solo podían contar con el apoyo de sus socios o de su familia, razón por la cual muchos miembros, incorporaron a sus hijos y esposas a las labores de la cooperativa.

Como nosotros trabajábamos con la cooperativa, era con nosotros mismos con quienes trabajábamos. Mi esposa, junto a otras 9 mujeres: chapodaban, limpiaban el tomate y arralaban el maíz. Lo único que no hacían era regar... nosotros los varones hacíamos todo lo que ellas hacían más regar y aplicar el veneno. (Blandón, 2015).

En la cita anterior, de manera clara se ve la integración de las mujeres al trabajo productivo, y la distribución específico de roles. Si bien, ellas tomaban parte en múltiples actividades, había algunas de esas actividades, por el alto riesgo que implicaban, desempeñadas únicamente por los hombres. Una de esas actividades era la aplicación de los plaguicidas para el control de plagas. El salario en las cooperativas de Villa Chagüitillo, a pesar de las circunstancias de ese entonces, era suficiente para el campesinado: Cuando había buena ganancia, que dependía del mercado, se sacaba más o menos 100,000 córdobas, claro que eso en los años 80' (Blandón, 2015).

Durante esta década, debido a la difícil situación política y económica que vivían el país, a consecuencia de la guerra de agresión de los Estados Unidos en contra de la revolución, se generó un proceso inflacionario y la devaluación de la moneda. Esta situación afectó en alguna medida el proceso productivo, aunque debe de señalarse que el gobierno siempre mantuvo el financiamiento con el fin de sostener la producción.

En el contexto de la revolución, el papel de la mujer se realzó en las cooperativas, siendo reconocido dentro de la estructura de funcionamiento. Es importante recordar 
que la mujer siempre ha estado involucrada en los procesos productivos campesinos, sin embargo, es con la revolución y el impulso de las cooperativas donde se les reconoció $\mathrm{su}$ valioso aporte dentro de esta forma colectiva de producción. Blandón recuerda las enseñanzas de su mamá: Bueno, a medida que uno se va criando va aprendiendo el trabajo, uno sigue a sus padres y se va fijando lo que ellos hacen y claro a uno lo ponen a hacer lo mismo para ayudar. Yo aprendí con mi mamá que me llevaba al siembro. (Blandón, 2015).

La cultura del trabajo se transmite de generación en generación, por medio de la convivencia, dentro de un proceso de observación-práctica que inicia desde la niñez. En este entorno se repiten patrones productivos que fortalecen la identidad grupal o local. En el caso de los indígenas y campesinos de Villa Chagüitillo, el aprendizaje de la práctica agrícola del maíz y frijoles se trasmitía vía enseñanza paterna. Las prácticas surgidas de la experiencia productiva colectiva en las cooperativas, reestructuraron la cultura del trabajo en el territorio, revalorizando la integración familiar. Parte de estos espacios sociales eran los cultivos:

... un día de trabajo en mí tiempo en caso que sembráramos maíz, se le dedicaba todo el día a esa siembra, no menos 8 horas, trabajábamos como cinco personas en una manzana... nosotros platicábamos en cualquier parte sobre la producción y cómo le iba a cada uno en la cosecha de la familia. Así, se construyen los lazos de amistad. (Blandón, 2015).

Se puede interpretar que el trabajo era el agente cohesionador de los grupos sociales en el territorio. Pero también existían otros espacios de interacción social, como lo cuenta don Luis:

El INTA hacia reuniones donde se hablaba de las cosechas y nos presentaban plantas de diferentes parcelas, y ahí nos conocíamos todos. En la actualidad en todo el territorio de Chagüitillo ya no hay cooperativas, pero creo que el INTA aún hace sus reuniones con pequeños productores que han ido quedando. (Blandón, 2015).

A principios de la década del 90 se instaura un nuevo régimen político que abraza el neoliberalismo, cuyas acciones gubernamentales van dirigidas a una contrareforma agraria. Las políticas públicas implementadas, dirigidas al sector rural apuntaban al desmantelamiento de las cooperativas y las privatizaciones de la tenencia de la tierra.

Uno de esos cambios fue el cierre de los grandes proyectos de desarrollo impulsado por la revolución, los impulsados para desarrollar la agroindustria. Según don Larry Monje,

.. Había una empresa búlgara que se llamaba: "Proyecto Los Búlgaros", sembraban grandes hectáreas de tomate y lo empacaban para exportar, y llego aquí hasta en los años noventa. (Monje, 2015).

La población mantenía contacto y relaciones con los complejos agroindustriales como el proyecto de financiado por el gobierno búlgaro, representando una importante fuente de trabajo -como se señaló-- y sus relaciones con las cooperativas. Este proyecto se vería afectado por las medidas neoliberales, y los nuevos complejos como: "Hortifrutas", la "Hidropónica", vistos como progreso, escondían la dramática situación del acoso a las cooperativas.

Una de las medidas más radicales tomadas por el gobierno neoliberal de doña Violeta, a principios de la década del noventa, fue el corte del subsidio y con la privatización de la banca, que acabarían los préstamos a los productores pequeños. A esto se debe agregar el conflicto por la propiedad, lo cual hace a las cooperativas vulnerables. Ernaldo José Rocha de 28 años originario de Villa Chagüitillo, graduado de Turismo sostenible 
y actual docente de francés menciona que: Las cooperativas fueron desapareciendo gradualmente durante la década de los 90 , porque ya no tenían el financiamiento que en los 80' recibían. A veces no lograban sacar suficiente producción y sin la ayuda que les daba el gobierno no lograba recuperar lo invertido, tuvieron que dedicarse a otras cosas. (Rocha, 2015)

Como bien lo menciona Ernaldo Rocha, el no ser sujeto de financiamiento jugó un papel negativo crucial para las cooperativas. El gobierno neoliberal de Doña Violeta dejó de apoyar estas iniciativas colectivas que eran uno de los principales estandartes productivo de la revolución. Don Luis Blandón narra como la cooperativa de la que formo parte, desapareció ante la problemática del financiamiento:

La cooperativa desapareció porque ya no había dinero para trabajar, en los 90' ningún banco quería ayudarnos con crédito. La cooperativa desaparece más o menos en el año 1995, éramos 45 socios los que nos vimos afectados. (Blandón, 2015)

Ante una situación agobiante, a consecuencia de la falta de financiamiento y la aparición de nuevas empresas agrícolas de corte capitalistas, los miembros de las cooperativas son forzados a deshacerse de sus medios de producción, vendiendo las tierras. Esta situación crea un nuevo escenario laboral y productivo ya que muchos de sus habitantes tendrán que trabajar en empresas como peones o jornaleros.

Pese a la nueva configuración productiva, donde el cultivo del arroz llega hasta Chaguitillo, como producto de la concentración de la tierra en pocas manos y el desmantelamiento de las cooperativas, las hortalizas (cebolla, tomate, zanahoria) seguían teniendo un peso importante. Esta vez competían con el arroz acuático y el acopio y beneficiado de café. No obstante, el maíz y frijol no desaparecieron, los grandes finqueros los siguieron cultivando pero no con la lógica de autoconsumo, sino para su comercialización. Ciertos pequeños productores mantuvieron su lógica de autoconsumo. Cabe destacar, que con la tierra en manos de los de los grandes propietarios de tierra, los pequeños productores optaron por la actividad pecuaria.

Desde el año 2000 hasta la actualidad, no se han producida cambios significativos en la tenencia de la tierra. El único cambio experimentado en Villa Chagüitillo durante este período, ha sido la desaparición, y asentamiento, de diferentes empresas, algunas de ellas bajo régimen de zonas francas abiertas en la década noventa, al igual que la hidropónica.

En la actualidad, la mayoría de la población ha migrado a otras formas de empleo, combinando, además de prácticas de cultivo de rubros conocidos, la activada pecuaria y la comercialización a pequeña escala. La impronta del trabajo campesino identifica a muchos pequeños productores y el conocimiento de la cadena productiva y los ciclos de producción le ha dado herramientas para defenderse de las trampas del mercado. José Martín Flores, un señor de 53 años de edad, quien se auto identifica indígena del lugar, sembrador de maíz y productor pecuario señala:

...he quedado solo con el maíz y es para comercio. El mercado es lo que te define lo que vas cosechando. Sébaco es un centro de acopio gigante; parte del comercio queda en Sébaco y lo otro va al Mayoreo y el Oriental. La experiencia te dice qué cosechar, por ejemplo, en diciembre genera más venta de hortalizas. Así vas teniendo dominio de lo que el mercado va demandar por temporada. (Flores, 2015)

Un aspecto interesante que apunta José flores, es la articulación con el mercado. Tal articulación se puede entender como una relación de poder, que puede definirse como 
"demanda-condicionante". La demanda de rubros como el maíz en los mercados nacionales ejerce presión a los productores de Villa Chagüitillo y los condiciona a cultivar este rubro por sobre otros.

El proceso de transformación vivido en Villa Chagüitillo, y el recorrido a partir de la década de los setenta hasta la actualidad, se resume en la tabla 1. En ella se dan a conocer los rubros agrícolas de mayor peso en cada uno de los períodos establecidos y el impacto que estos han tenido en la vida de sus habitantes:

Tabla 1. Matriz comparativa de la dinámica productiva por décadas en Villa Chagüitillo.

\begin{tabular}{|c|c|c|c|c|}
\hline $\begin{array}{l}\text { Aspecto por } \\
\text { tiempo. }\end{array}$ & $70^{\prime}$ & $80^{\prime}$ & $90^{\prime}$ & Actualidad \\
\hline $\begin{array}{l}\text { Estructura } \\
\text { social. }\end{array}$ & $\begin{array}{l}\text { Tipo señorial, con } \\
\text { el control de la } \\
\text { tierra en manos de } \\
\text { terratenientes. }\end{array}$ & $\begin{array}{l}\text { Con base en } \\
\text { un sentido de } \\
\text { asociatividad, con } \\
\text { las tierras en manos } \\
\text { de cooperativas. }\end{array}$ & $\begin{array}{l}\text { Con base en el sentido } \\
\text { de privatización } \\
\text { capitalista, con la } \\
\text { tierra en manos de } \\
\text { emporios comerciales } \\
\text { y grandes productores } \\
\text { capitalistas. }\end{array}$ & $\begin{array}{l}\text { Con base en el sentido } \\
\text { de privatización } \\
\text { capitalista, con la tierra } \\
\text { en manos de emporios } \\
\text { comerciales y grandes } \\
\text { productores capitalistas. }\end{array}$ \\
\hline $\begin{array}{l}\text { Rubro } \\
\text { comercial } \\
\text { principal. }\end{array}$ & El algodón. & Las hortalizas & $\begin{array}{l}\text { Las hortalizas, } \\
\text { anexando la } \\
\text { producción de arroz } \\
\text { y los procesos de } \\
\text { preparado de café }\end{array}$ & $\begin{array}{l}\text { La cebolla, arroz } \\
\text { y los procesos de } \\
\text { preparación de café. } \\
\text { Con la producción de } \\
\text { granos básicos en los } \\
\text { finqueros. }\end{array}$ \\
\hline $\begin{array}{l}\text { Estrategia de } \\
\text { subsistencia. }\end{array}$ & $\begin{array}{l}\text { Siembra de maíz, } \\
\text { arroz y frijoles, } \\
\text { como elemento } \\
\text { de la identidad } \\
\text { c a m p e s i n o - } \\
\text { indígena. }\end{array}$ & $\begin{array}{l}\text { Siembra de maíz, } \\
\text { arroz y frijoles, } \\
\text { como relemento } \\
\text { de la identidad } \\
\text { c a m p e s i n o - } \\
\text { indígena. }\end{array}$ & $\begin{array}{l}\text { Diversificación del } \\
\text { trabajo e integración a } \\
\text { emporios comerciales, } \\
\text { con prevalencia en } \\
\text { algunos productores } \\
\text { del cultivo de maíz y } \\
\text { otros granos básicos. }\end{array}$ & $\begin{array}{l}\text { Creación de micro- } \\
\text { negocios que } \\
\text { suplementan el ingreso } \\
\text { económico insuficiente } \\
\text { de la integración a } \\
\text { emporios comerciales } \\
\text { y otros empleos } \\
\text { asalariados. }\end{array}$ \\
\hline
\end{tabular}

Fuente propia.

\section{Villa Chagüitillo en la actualidad}

El proceso de transformación en Villa Chagüitillo, refleja una tendencia a la venta de la fuerza de trabajo. En este apartado se hará referencia al mosaico de trabajos que se dan en la comunidad y que de alguna manera ha reconfigurada la unidad doméstica. José
Flores es un productor pecuario, que ante la necesidad de la diversificación del trabajo, junto a su familia, ha redistribuido los roles ampliando el abanico de estrategias:

... yo me dedico medio tiempo al ganado y mi esposa es docente, además, yo también trabajo para el gobierno como delegado del ministerio agropecuario. (Flores, 2015) 

producción ganadera y su esposa es docente, ejerciendo también un empleo especializado. En esta familia se puede ver la combinación del trabajo asalariado con el productivo familiar.

Al hacerse una comparación entre la unidad doméstica de José Flores con la forma de trabajo de las cooperativas de Villa Chagüitillo durante la década de los ochenta, la principal diferencia radica en que toda la unidad familiar no se enfoca en una única labor agrícola, como durante la revolución. Ahora comprende un número de opciones que permiten completar el ingreso no solventado con el trabajo asalariado.

Otro ejemplo de la reconfiguración de la unidad doméstica actual de Chagüitillo, es el caso familiar de Don Larry Monje. Él no es productor agropecuario pero su configuración en la unidad doméstica es semejante a la de José Flores. Al preguntarle qué trabajos hacia su familia él respondió: $M i$ esposa tiene su propio negocio de ropa, mis hijos participan en las actividades de la casa, mientras yo salgo a ENACAL a trabajar como inspector. (Monje, 2015).

Con los modelos de unidad doméstica señalados arriba, la producción agrícola familiar se ve desplazada por el proceso de venta de la fuerza de trabajo, en lo que se puede denominar como proletarización (cultura asalariada). Los beneficios de café pintan el papel de opción de trabajo y de proletarización, ya que este trabajo remunerado genera ingresos rápidos (aunque no lo suficiente) afectando muchas unidades domésticas.

En el año 2015 realicé un sondeo para estimar el impacto de los beneficios de café en la cultura del trabajo. En el siguiente gráfico se

Revista Humanismo y Cambio Social. Número 6. Año 3. Julio - Diciembre 2015
La unidad doméstica de José Flores es un puede observar
$\begin{aligned} & \text { caso interesante: trabaja en el gobierno } \\ & \text { de medio tiempo (MAG), se dedica a la }\end{aligned}$

Revista Humanismo y Cambio Social. Número 6. Año 3. Julio - Diciembre 2015
La unidad doméstica de José Flores es un puede observar
$\begin{aligned} & \text { caso interesante: trabaja en el gobierno } \\ & \text { de medio tiempo (MAG), se dedica a la }\end{aligned}$

Revista Humanismo y Cambio Social. Número 6. Año 3. Julio - Diciembre 2015
La unidad doméstica de José Flores es un puede observar
$\begin{aligned} & \text { caso interesante: trabaja en el gobierno Chagüitillo: } \\ & \text { de medio tiempo (MAG), se dedica a la }\end{aligned}$

puede observar los tipos de trabajo en Villa

Gráfico 1. Tipos de Trabajo en Villa Chagüitillo.

Revista Humanismo y Cambio Social. Número 6. Año 3. Julio - Diciembre 2015
La unidad doméstica de José Flores es un puede observar
$\begin{aligned} & \text { caso interesante: trabaja en el gobierno } \\ & \text { de medio tiempo (MAG), se dedica a la }\end{aligned}$

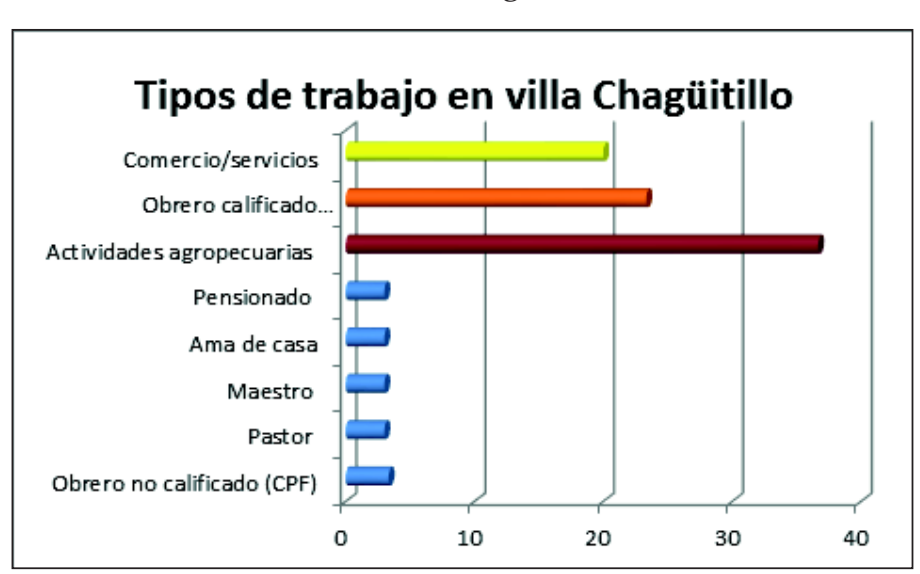

Fuente propia.

En el gráfico se observa un $37 \%$ se desempeña en la actividad productivas de los cuales el $23 \%$ se dedican al beneficiado de café; y el $63 \%$ se dedica a otras actividades.

Los trabajos no agrícolas destacan que el 23\% son obreros calificados (artesanos, albañiles, soldadores carpinteros y operadores de maquinaria); seguido en porcentaje de los que se dedican a actividades comerciales $(23 \%)$; otros se dedican a trabajos como vigilantes (CPF), y un pequeño porcentaje son maestros/as $(3 \%)$, pastores $(3 \%)$, ama de casa $(3 \%)$, pensionados $(3 \%)$,

La actividad económica realizada por los beneficios tiene enorme impacto en la comunidad. Estas empresas contratan trabajadores por temporada (un promedio de 3 a 4 meses.) Durante este período, según Wilder José Huerta los obreros pueden desempeñar cualquiera de las tareas tales como el secado de café (se pone el grano al patio para asolear), enfardar (levantar del suelo el grano luego del secado), ensacar (empacar los granos en sacos) o el trillado (Huerta, 2015). 
... en los beneficios de café uno trabaja al día, en el día uno puede sacar C\$130 córdobas. El café que viene del norte se pone al patio a secado, ahí se rastrilla y como a los 4 o 6 días (dependiendo del tipo de café) ya queda para procesar.

Durante dura la temporada de café y los beneficios están laborando a toda su capacidad, los obreros agrícolas, siente seguridad económica, cosa contraria cuando termina el trabajo y allí surgen las estrategias de sobrevivencia. Al entrevistar Wilder Huerta, estaba trabajando en el taller de un amigo debido a que la temporada de contratación en los beneficios ya había terminado.

Otro punto que debe ser tomado en cuenta es el ingreso económico, pues el monto representa un buen aliciente y seguridad económica para el trabajador y su familia. Si los beneficios pagan por día un promedio de C\$ 130 córdobas, representando por semana un estimado mensual de $\mathrm{C} \$ 3640$ córdobas, con este salario surge la pregunta ¿qué tan significativo es este ingreso en contraste con los costos de vida nicaragüense?

Para tener una idea del costo de vida, una buena fuente es la canasta básica, siguiendo al Instituto Nacional de Información de Desarrollo (INIDE) y al Banco Central de Nicaragua, el valor de la canasta básica hasta diciembre 2014 era de $\mathbf{C} \$ 12,249$ córdobas (Banco Central de Nicaragua, 2015). Si se compara el salario que devenga el obrero agrícola del beneficio de café, siendo un salario de los más importantes para los trabajadores en Chagüitillo, no llega a cubrir la mitad de la canasta básica.

$\mathrm{Si}$ se tomara en cuenta los costos de la canasta básica que comprende: alimentación, gastos del hogar y vestuario, sumaría C $\$ 8,216$ córdobas, el salario recibido no llega a cubrir esta necesidad. Como se sabe el salario, no se utiliza únicamente a la alimentación sino a cubrir otras necesidades, obligando a los trabajadores de Chagüitillo, a buscar otras fuentes de ingreso.

Es un hecho que los salarios son bajos y no cubren lo mínimo de las necesidades del trabajador del campo, pero están en consonancia con lo que estipula la ley en materia salarial. Según la legislación vigente para el 2015, el salario mínimo para el sector agropecuario es de C\$3,187 córdobas (ver acuerdo ministerial ALTB-01-02-2015, Ley No. 185 y Ley del salario mínimo No. 625, Ministerio del Trabajo, 2015).

Si se parte del salario mínimo para el sector agropecuario correspondiente a 30 días, el salario por día es de $\mathrm{C} \$ 106$ córdobas al día. Eso significa que un $90 \%$ de los trabajadores de Chagüitillo tiene un pago mensual que no cubre las necesidades. Es importante destacar que se ha tomado el caso de los beneficios de café por ser el más representativo a nivel de la población en estudio.

El promedio general de ingreso de las familias de Chagüitillo es de $C \$ 5,733$ córdobas, por debajo del coste de la canasta básica.

Gráfico 2. Niveles de Ingreso en la población de Villa Chagüitillo.

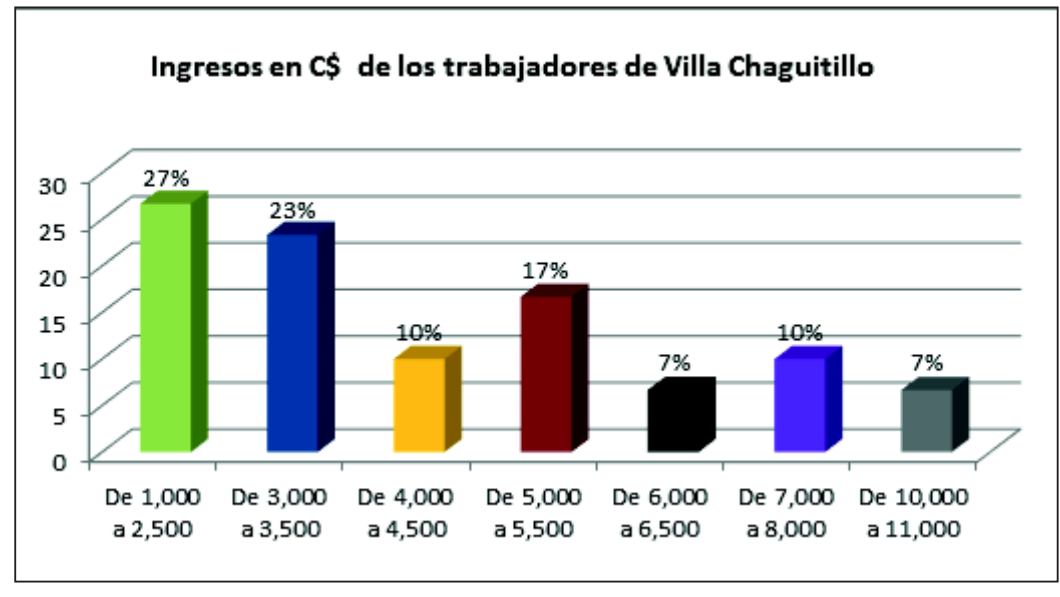

Fuente propia. 
En términos generales, un $17 \%$ de la población percibe ingresos mensuales entre C $\$ 2000$ a C $\$ 2500$ córdobas, para el 23\% los ingresos están entre $C \$ 3000$ a $C \$ 3500$; un $10 \%$ tiene ingresos entre $\mathrm{C} \$ 4000$ a $\mathrm{C} \$ 4500$, otro $23 \%$ percibe ingresos entre $C \$ 5000$ a $C \$ 5500$, el $17 \%$ percibe ingresos entre $C \$ 7000$ a $C \$ 8000$ y los ingresos mayores van entre $C \$ 15,000$ a $\mathrm{C} \$ 20,000$ córdobas que son percibidos solo por un $10 \%$ de la población.

Esto quiere decir que el único segmento poblacional en la comunidad que cuenta con el acceso a la canasta básica completa, y su ingreso le permite destinar su presupuesto a otros fines, es el 10\%.

Volviendo al caso de los beneficios de café, donde un $26 \%$ de la población labora en estos centros y cuyo salario mensual (durante la temporada) es $\mathbf{C} \$ 3,640$ córdobas. Este dato no difiere del porcentaje de población que percibe ingresos entre $\mathrm{C} \$ 3000$ a $\mathrm{C} \$ 3500$, siendo mínima la variación (3\%) del segmento de $23 \%$ a $26 \%$.

A continuación se mostrara el gráfico de los niveles de egreso de la población, para hacer el contraste con los ingresos percibidos:

Gráfico 3. Niveles de Egreso en la población de Villa Chagüitillo.
Ahora se muestra el egreso, es decir, los gastos promedios que se hacen en cada hogar. Un $27 \%$ de la población tiene gastos o egresos mensuales entre $\mathrm{C} \$ 1000$ a $\mathrm{C} \$ 2500$ córdobas, el 23\% entre C $\$ 3000$ a C $\$ 3500,10 \%$ entre $C \$ 4000$ a $C \$ 4500,17 \%$ entre $C \$ 5000$ a $\mathrm{C} \$ 5500,7 \%$ entre $\mathrm{C} \$ 6000$ a $\mathrm{C} \$ 6500,10 \%$ entre $\mathrm{C} \$ 7000$ a $\mathrm{C} \$ 8000$, y un último segmento, correspondiente al $7 \%$ entre C\$10000 a C $\$ 11000$ córdobas.

Se encuentra un $23 \%$ de la población que gasta entre $C \$ 3000$ a $C \$ 3500$ córdobas mensuales, la misma cantidad de población que percibe un nivel de ingreso del mismo rango. El $27 \%$ de la población, siendo el número más considerable, trata de hacer gastos mínimos en el mes, lo que tiene coherencia al ser la mayoría de la población la que percibe bajos ingresos; en el nivel más alto de egresos se ubica un $7 \%$ de la población está en relación al 10\% de la población que percibe el nivel más alto de ingresos entre $C \$ 15000$ a $C \$ 20000$ córdobas.

El $27 \%$ de la población, haciendo los gastos mínimos para su subsistencia, son la representación más significativa de las restricciones a las que la comunidad se ve expuestas por imposición del panorama socioeconómico en la actualidad, y se aduce son las familias con un abanico menor de estrategias de subsistencia, donde la unidad

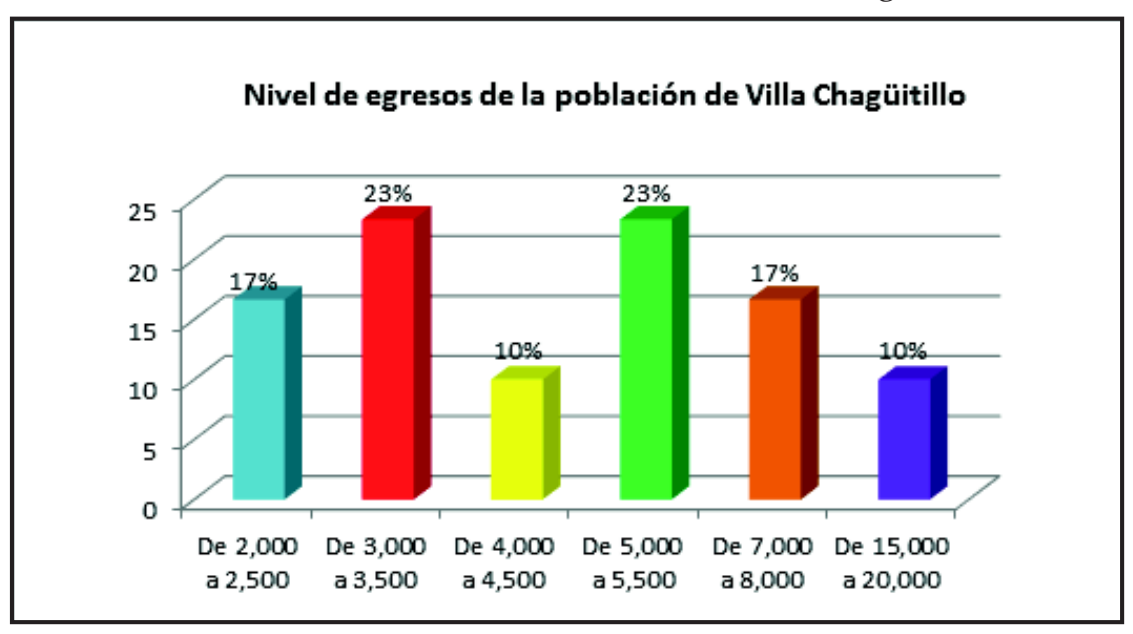
doméstica no se ha diversificado y cuente con solo una entrada económica.

Fuente propia. 
Cuadro 2. Relación entre ingreso y egreso en la población de Villa Chagüitillo.

\begin{tabular}{|c|c|c|c|c|c|c|c|c|c|}
\hline \multirow{2}{*}{\multicolumn{2}{|c|}{ De 1,000 a 2,500}} & \multicolumn{7}{|c|}{ Nivel de egreso en la población de Villa Chagüitillo } & \multirow[b]{2}{*}{ Total } \\
\hline & & \multirow{2}{*}{$\begin{array}{c}\begin{array}{c}\text { De } 3,000 \\
\text { a 3,500 }\end{array} \\
17 \%\end{array}$} & \multirow{2}{*}{$\begin{array}{c}\text { De } 4,000 \\
\text { a } 4,500 \\
0\end{array}$} & \multirow{2}{*}{$\begin{array}{c}\begin{array}{c}\mathrm{De} \\
5,000 \mathrm{a} \\
5,500\end{array} \\
0\end{array}$} & \multirow{2}{*}{$\begin{array}{c}\text { De } \\
6,000 \mathrm{a} \\
6,500 \\
0\end{array}$} & \multirow{2}{*}{$\begin{array}{c}\text { De } \\
7,000 \mathrm{a} \\
8,000 \\
0\end{array}$} & \multirow{2}{*}{$\begin{array}{c}\text { De } \\
10,000 \mathrm{a} \\
11,000 \\
0\end{array}$} & \multirow[b]{2}{*}{0} & \\
\hline \multirow{6}{*}{$\begin{array}{c}\text { Nivel de } \\
\text { ingresos de } \\
\text { la población } \\
\text { de Villa } \\
\text { Chagüitillo }\end{array}$} & $\begin{array}{c}\text { De } 2,000 \mathrm{a} \\
2,500\end{array}$ & & & & & & & & $17 \%$ \\
\hline & $\begin{array}{c}\text { De } 3,000 \mathrm{a} \\
3,500\end{array}$ & $10 \%$ & $13 \%$ & 0 & 0 & 0 & 0 & 0 & $23 \%$ \\
\hline & $\begin{array}{c}\text { De } 4,000 \mathrm{a} \\
4,500\end{array}$ & 0 & $10 \%$ & 0 & 0 & 0 & 0 & 0 & $10 \%$ \\
\hline & $\begin{array}{c}\text { De } 5,000 \text { a } \\
5,500\end{array}$ & 0 & 0 & $10 \%$ & $13 \%$ & 0 & 0 & 0 & $23 \%$ \\
\hline & $\begin{array}{c}\text { De } 7,000 \mathrm{a} \\
8,000\end{array}$ & 0 & 0 & 0 & $3 \%$ & $7 \%$ & $7 \%$ & 0 & $17 \%$ \\
\hline & $\begin{array}{c}\text { De } 15,000 \\
\text { a } 20,000\end{array}$ & 0 & 0 & 0 & 0 & 0 & $3 \%$ & $7 \%$ & $10 \%$ \\
\hline \multicolumn{2}{|c|}{ Total } & $27 \%$ & $23 \%$ & $10 \%$ & $16 \%$ & $7 \%$ & $10 \%$ & $7 \%$ & $100 \%$ \\
\hline
\end{tabular}

Fuente Propia.

En la tabla de relación de ingreso y egreso se puede ver de forma más detallada, el porcentaje de familias que tienen un ingreso específico del cual se deriva su egreso. Este planteamiento señala al 10\% de la población con el más alto nivel de ingreso que va de $\mathrm{C} \$ 1500$ a C $\$ 20000$ córdobas quienes tienen un gasto mensual de $\mathrm{C} \$ 7000$ a $\mathrm{C} \$ 11000$ córdobas. En el otro extremo, el $40 \%$, --un poco menos de la mitad de la población-accede a productos y servicios, siempre y cuando sus gastos no excedan montos entre C \$1000 a C \$3500 córdobas, correspondiente a los ingresos de la familia.

Los datos anteriormente expuestos, sugieren que la diversificación del trabajo y la variedad de estrategias de subsistencia reflejan la situación socioeconómica actual de Chagüitillo. El acceso a bienes y servicios están ligados de manera directa al flujo del ingreso.

\section{Conclusiones}

A manera de conclusión preliminar, se puede señalarquelas políticas degobiernoenmateria laboral y productiva, tienen efecto directo en los cambios de la dinámica de los territorios rurales y semi-rurales, especialmente en las políticas de financiamiento a los pequeños, medianos productores agropecuarios, grandes comercializadoras y complejos agroindustriales. Políticas inscritas dentro de un mercado nacional que actúa en las concepciones colectivas acerca de lo que se entiende como el trabajar (como acto individual y colectivo) dentro del sector rural, estableciendo el cómo y cuándo trabajar.

De acuerdo a este estudio se puede afirmar que a medida que el mercado y los procesos de urbanización vayan calando en áreas rurales o semi-rurales (tal como Villa Chagüitillo) la 
necesidad de la especialización continuará agudizándose. Los emporios comerciales establecen las pautas para la incorporación de la fuerza laboral de estas áreas sociales dentro de sus dinámicas, incidiendo en la formas de vida de estas áreas sociales.

En relación al tema de los ingresos por medio de la venta de la fuerza de trabajo, concerniente a la mayoría de la población laboralmente activa, de Villa Chagüitillo, se encuentra un problema salarial, que de alguna manera afecta a los trabajadores rurales, como su relación con la canasta básica. El estudio demuestra que no hay correspondencia entre salario mínimo y canasta básica, siendo el primero inferior.

Por último, debe recalcarse que para la comprensión del proceso de transformación de la dinámica productiva, se hace necesarios conocimientos diversos y métodos adecuados de investigación social. Por ello, un estudio de esta naturaleza requiere de un enfoque interdisciplinario, sea individual o por medio de un colectivo de trabajo con especialistas de las diferentes áreas sociales. De aquí el carácter provisional del estudio.

\section{Referencias bibliográficas}

Banco Central de Nicaragua. (2015). Canasta Básica. Managua: IPC-BCN.

Cruz-Sequeira, A. J. (2005). ¿Qué ocurrio en Nicaragua? Estudio ralizado para el proyecto análisis político y escenarios prospectivos del PNUD. INCAE.

Fromm, E., \& Maccoby, M. (1990). Sociopsicoanálisis del campesino mexicano. Estudio de la economía y la psicología de una comunidad rural. México: Fondo de cultura económica.

García, A. (1990). La reforma agraria como problema Latinoamericano. En O. Nuñes, Lo Agrario teoría y métodos. San José, Costa Rica: Editorial Universitaria Centroamericana.

Ministerio del Trabajo. (2015). Acuerdo
Ministerial ALTB-01-02-2015. Managua: Ministerio del Trabajo.

Moreno, I. (1997). Trabajo, ideología sobre el trabajo y culturas del trabajo. Revista Andaluza de Relaciones Laborales, 9-28.

OIT. (1953). Poblaciones indígenas. Condiciones de vida y de trabajo de las poblaciones autóctonas de los países independientes. Ginebra: Oficina Internacional del Trabajo.

\section{Entrevistas citadas}

Blandón, L. L. (20 de Abril de 2015). Gestión de los elementos culturales en función del turismo comunitario en Chagüitillo, 2015. (J. Torres, Entrevistador)

Flores, J. M. (20 de abril de 2015). Gestión de los elementos culturales en función del turismo comunitario en Chagüitillo, 2015. (J. Torres, Entrevistador)

Huerta, W. J. (21 de abril de 2015). Gestión de los elementos culturales en función del turismo comunitario en Chagüitillo, 2015. (J. Torres, Entrevistador)

Monje, L. (20 de Abril de 2015). Gestión de los elementos culturales en función del turismo comunitario en Chagüitillo, 2015. (J. Torres, Entrevistador)

Rocha, E. J. (21 de abril de 2015). Gestión de los elementos culturales en función del turismo comunitario en Chagüitillo, 2015. (J. Torres, Entrevistador) 